\title{
El averroísmo contemporáneo. Intelecto, imaginación y la cuestión del humano
}

\author{
Contemporary Averroism. \\ Intellect, Imagination and the Human Question
}

\author{
MAURICIO GUILLERMO AMAR DÍAZ \\ UNIVERSIDAD DE CHILE
}

Recibido: 16/10/2019 Aceptado:16/03/2020

\begin{abstract}
RESUMEN
El artículo indaga en la reemergencia de ciertos principios que la Edad Media vinculó al pensamiento de Averroes en pensadores contemporáneos como Giorgio Agamben, Roberto Esposito, Emanuele Coccia y Jean Baptiste Brenet. La eternidad del mundo y la separación del itnelecto vuelven a aparecer como sustento de una filosofía capaz de poner en tela de juicio ideas fundamentales de la modernidad como la de sujeto o persona, sin por ello entramparse en el nihilismo.
\end{abstract}

\section{PALABRAS CLAVE \\ AVERROÍSMO, IMAGINACIÓN, INTELECTO, HUMANISMO, POTENCIA}

\section{ABSTRACT}

The article investigates the re-emergence of certain principles that the Middle Ages linked to Averroes' thinking on contemporary thinkers such as Giorgio Agamben, Roberto Esposito, Emanuele Coccia and Jean Baptiste Brenet. The eternity of the world and the separation of the intellect appear again as the support of a philosophy capable of questioning fundamental ideas of modernity such as that of subject or person, without for that reason becoming trapped in nihilism.

KEYWORDS

AVERROISM, IMAGINATION, INTELLECT, HUMANISM, POTENCY

(C) Contrastes. Revista Internacional de Filosofía, vol. XXV Nº1 (2020), pp. 45-59. ISSN: 1136-4076

Departamento de Filosofía, Universidad de Málaga, Facultad de Filosofía y Letras Campus de Teatinos, E-29071 Málaga (España) 


\section{El AVERROÍ́SMO COMO RESTO EN LA FILOSOFÍA}

EN 1270 y 1277 EL OBISPo Éttiene Tempier, llevó a cabo dos condenas contra una docttrina filosófica que parecía diseminarse por la escuela de teología de la Universidad de París. Se le conocía como averroísmo y fue disputada por la autoridad religiosa en 219 tesis, entre las cuales algunas han devenido famosas como la eternidad del mundo, la negación de la providencia divina y la idea de un intelecto único. Por cierto, ha existido una gran discusión sobre la existencia real de un grupo de cristianos que se hayan podido definir como averroístas, cosa poco demostrable por la heterodoxia de los pensadores más relevantes que habrían sido designados por tal nombre como Siger de Bravante y Boecio de Dacia. Más aún, todo se distorsiona si tenemos presente que una acusación dirigida al averroísmo fue la de admitir una doble verdad, de acuerdo a las posibilidades de la filosofía y la religión, tesis que no defiende ni Averroes (Ibn Rušd) ni Bravante ni Dacia. Si existió algo como un averroísmo latino, habría que entenderlo, por una parte, como una defensa de la «filosofía como profesión, de una profesión intelectual, de una felicidad corporativista y elitista» (De Libera, 2000, 67), fenómeno intelectual que sí tuvo enormes consecuencias para el pensamiento europeo a pesar de las condenas eclesiásticas. En segundo lugar, como una adscripción al interior del mundo cristiano de la doctrina del intelecto separado y la eternidad del mundo, que fue pensada en un contexto cultural islámico.

Esto de ninguna manera oblitera la relevancia de Averroes y en general de la filosofía árabe, que como bien dice De Libera fue la verdadera iniciadora de Europa en la filosofía y prácticamente omnipresente a la hora de leer a los clásicos griegos (Cf. Ibíd., pp. 44-45). Y más aún, dado que los medievales no conocieron algunos textos fundamentales de Averroes como el Fasl Al-Maqâl (Sobre la armonía entre la Religión y la Filosofia) y el Tahâfut al-Tahâfut (La incoherencia de la incoherencia), no debe confundirse el averroísmo latino con el pensamiento de Ibn Rušd, pero tampoco se debe obliterar la relevancia para la formación intelectual de los latinos medievales de la introducción de conceptos averroístas claramente divergentes respecto a la teología cristiana y que muchos de ellos hicieron suyos con el fin de pensar más allá de los estrechos límites que imponía sobre la filosofía.

Ninguno se llama a sí mismo averroísta - dice Antonio Gagliardi-y también por este motivo, pareciera que el averroísmo se desvaneció en la nada. La unidad del intelecto, la doctrina que más que ninguna otra parece marcar una identidad averroísta, es una premisa que permanece escondida dentro de la escatología de la felicidad prometida por la ciencia (Gagliardi, 1998, p. 39).

Si existen momentos en los que se tiende a definir un pensamiento tal bajo el rótulo de averroísmo, debemos destacar al menos tres. El primero de 
ellos es la propia condena de Tempier, que al prohibir las tesis averroístas, en realidad las crea e indica a un grupo de teólogos como defensores de ellas. La segunda es la crítica que lleva a cabo Tomás de Aquino, que se aboca a refutar explícitamente el pensamiento de Averroes y subtitula su famoso texto De Unitate Intellectus «Contra Averroístas» de donde proviene, de hecho el mote «averroísmo» (Martínez Barrera, 2018). Esto hace del averroísmo en su propio tiempo una suerte de movimiento heterodesignado, que traerá consecuencias efectivas en la defensa de algunas tesis averroístas que figuras determinantes como Dante y bastante después Giordano Bruno y Baruch Spinoza harán suyas, éste último caso gracias al averroísta hebrero cretense Elia de Medigo (Licata, 2017). Por último, es en el siglo XIX Ernest Renan quien en su libro Averroes y el averroísmo, ensayo histórico, abre una vía de interpretación del averroísmo desde la modernidad, aislándolo en una época ya superada y lanzando desde el prefacio la idea de que «no tenemos nada o casi nada que aprender de Averroes, ni de los árabes, ni de la Edad Media» llamando al filósofo cordobés fanático y supersticioso admirador de Aristóteles (Renan, 1866, p. v y p. 54). «Con la obra de Renan -dirá Coccia-, tras siglos de condena teológica, comienza la época de una nueva forma más sutil y pérfida de damnatio, la forma histórica» (Coccia, 2008, p. 75).

Tanto para la teología como para la modernidad la figura de Averroes y la propagación de sus tesis bajo el rótulo de averroísmo parecen ser desechables. Se podría decir que en particular para la teología, el averroísmo resulta ser peligroso en tanto la concepción de un intelecto separado pone en riesgo el orden de la ciudad, que depende en última instancia de los premios y castigos que se puedan ejercer sobre individuos particulares (Aquino, 2005, p. 73), pero también porque en términos noéticos, Aquino acusará a Averroes de duo subiecta del inteligible en acto, creando un sujeto desdoblado en la imagen retenida en el alma y otro en el intelecto único (Brenet, 2013, p. 54). Para la modernidad, en cambio, Averroes funciona como un medieval paradigmático en tanto comentador de textos y no creador de pensamiento. De alguna manera, ambas formas de desechar el averroísmo comparten la premisa de que existe un individuo que coincide biológicamente con su capacidad intelectiva, en un caso para salvar el alma, en el otro para salvar al sujeto que ha devenido en su propio dios.

Resulta interesante, entonces, ver cómo Averroes y el averroísmo pueden funcionar como una especie de contra-teología y contra-modernidad al mismo tiempo, lo que parece abrirle camino en un pensamiento contemporáneo que precisamente busca, de alguna manera, salir del nihilismo en el que lo ha sumido la muerte de Dios, sin retornar a la teología. Y aunque han existido importantes esfuerzos por señalar también a Averroes como un preparador de la modernidad, debido a las lecturas en el siglo XX de su crítica al teólogo 
asharí Al-Ghazali y a la primacía que entrega a la filosofía por sobre la religión (Cf. Ábed Yabri, 2001), lo cierto es que es en los últimos veinte años que una lectura más atrevida, llevada a cabo más que por expertos en Averroes, por filósofos que ven en su pensamiento una posibilidad de repensar la modernidad occidental, que nuevamente el averroísmo comienza a amenazar las universidades y poner en tela de juicio los principios sobre los cuales se ha montado, con ayuda de la teología y de la modernidad, una antropología cuya premisa es la coincidencia entre razón y cuerpo.

Con este nuevo averroísmo, del que participan pensadores influyentes de nuestro tiempo como Giorgio Agamben y Roberto Esposito, La figura de Averroes pareciera enlazarse repentinamente a los estudios sobre biopolítica, gubernamentalidad (ambos campos de estudios abiertos por Michel Foucault), nuevas fenomenologías como la del pensamiento de Emanuele Coccia y agudas arqueologías filosóficas como las de estos mismos autores y Jean Baptiste Brenet. De nuevo, el averroísmo se vuelve, usando el término de Brenet, inquietante.

\section{EL AVERRoÍSMO, INQUIETANTE COMO UN DEMONIO}

Es necesario entender qué es lo que tiene de inquietante el averroísmo, tanto para quienes lo condenaron en el siglo XIII europeo como para la modernidad a estas alturas global. Brenet se pregunta porqué el monopsiquismo averroísta no fue simplemente desechado en su momento, porqué debió existir tanta animadversión por parte pensadores tan diferentes en doctrina como en épocas como Duns Scoto (que lo llamó «ese maldito»), Descartes, Leibniz, Herder o Renan ante un pensamiento que no contaba con poderes ni en la iglesia ni en el canon filosófico. «El sistema de Averroes fue difícil - dice Brenetporque él encarna una figura -un prototipo, tal vez- al que Freud llama das Unheimliche, 'lo ominoso' o la inquietante extrañeza». Aún más, «Averroes fue difícil, continuamente escandaloso, permanentemente gritando una navaja lista para desmembrarlo, porque él es, para sus lectores latinos, es decir para todos, extrañamente inquietante» (Brenet, 2018, p. 18).

Lo inquietante de Averroes es nada menos que su familiaridad, en tanto pensamiento que ha sido no superado sino deshechado, dejado en los márgenes, como un resto que atentaría contra los principios de la forma de vida y la noción de humanidad producida por la modernidad. Lo inquietante es «lo familiar escondido, disimulado, pero que resurge a la superficie» (Ibíd., p. 20), aquello que habiendo sido cercano queda en un estado de ocultación para mostrarse en tanto oculto. Y lo que a su vez es familiar-oculto resulta ambas cosas porque tiene capacidad de retorno. Es aquello que aparece cada vez que el proyecto de la razón occidental se esfuerza por darse consistencia interna. Ahí asecha la sin-razón, la a-mentia, el demonio como posesión. 
Demonizado queda el hombre por el intelecto separado. Tal es una acusación contra Averroes. El intelecto se sirve del cuerpo como lo hace un ente extraño; hace de él su instrumento, y a su vez el hombre invoca al intelecto, pues de otra manera no podría relacionarse con él. Toda una demonología se ha elaborado contra el averroísmo para dar cuenta de su fuerza extraña y apropiadora, desnaturalizante. «Potencialmente - dice Brenet- el hombre averroísta está siempre poseído, es siempre demoníaco ya que él ofrece al espíritu maligno un lugar vacío, un recipiente» de modo que sólo queda la alternativa de conjurar al averroísmo para que la inteligencia separada no pueda hacer del hombre su soporte e instrumento. «Es así como una antropología que no ve en el hombre un sujeto del intelecto, toma el riesgo de hacer de él el sustrato del demonio» (Ibíd., p. 61).

De hecho, como bien recalca Coccia, a propósito de La unidad del intelecto de Aquino, la fractura entre el individuo y el pensamiento lleva a la imposibilidad de dar forma a la ley, en tanto ella depende de cuerpos sobre los que debe ejercerse. La ley -dice- «no se caracteriza simplemente por un espacio y un tiempo específicos, esta presupone una forma de vida precisa, un tipo de hombre, una humanidad específica, o quizá la crea, la produce, la hace ser» (Coccia, 2008, p. 392). En lugar de ello, un intelecto separado, que entra en relación con los seres singulares sólo por medio de su unión con las formas de la imaginación (Averroes, 2004, p. 148), pone en cuestión la producción de una forma de vida en la que la ley gobierne de manera causal, pues tanto la imaginación como el propio intelecto son potencias receptivas cuya principal característica es la posibilidad y no el destino. En otras palabras, el averroísmo pone en tela de juicio toda providencia divina u orden del mundo fundado en la acción de Dios sobre los hombres.

Si encontramos una imagen demonológica en el averroísmo es también porque la doctrina del intelecto separado fue vista como un peligro para la teología. De hecho, La octava condena al averroísmo de 1277 acusa su pretensión de conocer la causa última por medio del intelecto, cosa contraria a los principios de la teología cristiana (Gagliardi, 2002, p. 51). Denuncia que haría sentido si de lo que se trata es de juzgar al demonio y su conflicto con el plan divino, en tanto el demonio utiliza al humano desde fuera, lo posee para que éste juegue a ser Dios, es decir, conocer la causa última, alcanzar la felicidad por medio de la vida especulativa tan cara al pensamiento aristotélico. Esta felicidad última fue entendida por el propio Averroes como un conocimiento directo de Dios, lo que evidentemente ponía en jaque en el Occidente latino el rol de la propia Iglesia Católica como conductora de la salvación de las almas. «El hombre - dice Gagliardi de alguna manera viendo un hilo secreto entre el 
averroísmo y Nietzsche- es un puente tendido entre el animal y Dios [...] la vida es este viaje a través de la total espiritualización de sí hasta devenir Dios» (Gagliardi, 1998, p. 41).

La única respuesta posible frente a esta propuesta demoníaca del averroísmo sería afirmar con toda radicalidad la coincidencia del intelecto con el cuerpo individual, arrojando al demonio fuera de los márgenes del pensamiento. Sólo de esta manera se puede conjurar la relación entre el intelecto separado y los seres singulares, esos dos sujetos que piensan -uno incorporal material y otro único y espiritual (De Libera, 2015, p. 213)- que a fin de cuentas terminan por introducir un riesgo demasiado grande para el modelo de la providencia divina. El averroísmo latino, entendido como una forma de pensamiento más que una escuela, dará con formulas para congeniar el cristianismo con las tesis del cordobés, pero su costo será la expulsión del canon filosófico y la habitación de otros lugares de la lengua, específicamente la poesía renacentista cargada de las premisas averroístas como bien pudo leer en su momento Ezra Pound en la escritura de Guido Cavalcanti (Byron, 2013, p. 88) y más cerca en el tiempo Agamben respecto a la poesía stilnovista en general (Agamben, 2006, pp. 179-189).

No es difícil entender porqué este problema teológico es la condición de posibilidad de la racionalidad moderna, que aísla a toda costa el riesgo de que el humano no piense, sea por locura o imbecilidad, rasgos que en la Edad Media estaban asociados a la posesión demoníaca. Como dirá Coccia, no es tanto el error respecto a la verdad lo que asusta a los racionalistas, sean teólogos medievales o filósofos modernos, sino la estupidez, la ausencia de pensamiento. Es a ella a la que «toda noesis debe lograr remover y explicar» (Coccia, 2008, p. 161). Averroes funciona, entonces, como una figura perversa, capaz de desestabilizar el orden social, de introducir una extrañeza en el pensamiento, hacer de él, por tanto un extranjero que al mismo tiempo haría posible todo pensar. Un dislocador de la subjetividad individual que no puede más que conducir a la locura y a la apostasía, que en un orden teológico no pueden sino coincidir.

No puede ser menos que inquietante, entonces, este nombre extranjero -por latinizado que sea- que plantea tan extraña teoría, que ni a medievales ni a modernos les acomoda incorporar porque para ello habría que repensar los cimientos mismos sobre los que se ha construido la idea de humano. Y tal vez sea, precisamente, el tiempo de pensar aquello.

\section{INTELECTO Y OBRA HUMANA}

Uno de los filósofos más relevantes que han hecho un acercamiento a la filosofía de Averroes en los últimos años es Giorgio Agamben. Y lo ha hecho con el fin de usar la tesis averroísta, siempre al lado de Dante, para abordar 
una cuestión que resulta tanto más inquietante para la modernidad. Se trata del problema de la inoperosidad ontológica del humano. En su famoso artículo La obra del hombre, comienza por analizar la obra aristotélica, intentando develar cierta confluencia del pensamiento aristotélico con una separación política al interior de la propia vida, que estaría en el punto originario de la filosofía occidental. Si la obra del zapatero es hacer zapatos, o la del músico dominar virtuosamente su instrumento, la obra que le concierne a la especie, dirá Aristóteles, necesariamente estará determinada por su participación en el lógos, orientando su propia praxis según éste, de modo que el bien del hombre será el «ser en obra del alma según la virtud» (De anima, 1098 a). Habría aquí una separación entre el vivir como tal y el vivir de acuerdo al logos que sería lo propio humano. Una antropogénesis que puede entenderse, de acuerdo a la Política, como una distinción entre vivir [zên] y vivir bien [êu zên], que estaría a la base de la separación entre bios y zôe.

«La determinación aristotélica de la obra del hombre implica -dice Agamben-dos tesis sobre la política, 1) en tanto se define en relación a un érgon la política es política de la operosidad y no de la inoperosidad, del acto y no de la potencia. 2) este érgon es, en última instancia, [...] 'una cierta vida 'que se define ante todo por la exclusión del simple hecho de vivir, de la vida desnuda» (Agamben, 2005, p. 370). El pensador italiano es tajante respecto al legado que estaría dejando Aristóteles a la política occidental. Legado aporético, dice porque «1) liga el destino de la política a una obra, que permanece inasignable con respecto a las actividades humanas singulares (tocar la cítara, hacer estatuas, producir zapatos), y 2) su única determinación es, en último análisis, biopolítica, en tanto descansa sobre una división y una articulación de la zoé. Lo político - continúa Agamben-se extrae de lo viviente por medio de la exclusión de una parte de su actividad vital como impolítica» (Ibídem).

Salir de la trama de la operosidad implica buscar una filosofía que recupere como aspecto central no la praxis sino la potencia. Por eso a Agamben le interesa Averroes y comprende también la influencia que éste ha tenido sobre el pensamiento de Dante. Para ambos, si bien el intelecto sigue siendo el lugar de realización de lo humano, el momento de la experiencia humana no sería tanto el acto como la potencia, que en su forma griega dynamis indica tanto poder como posibilidad. En otras palabras, habitar la potencia del intelecto implica no someterse al acto, sino avizorar siempre el no acto, que Agamben llama potencia de no. Para esto Agamben se vale de una cita que encontramos en el Comentario a la República de Platón de Averroes, donde éste indica que «Ya que la parte racional no existe en nosotros desde el principio en su perfección última y en acto, su existencia en nosotros sólo es potencial» (Averroes, 2011, p. 91). 
Resulta especialmente interesante que Averroes aparezca nuevamente al final de la gran obra de Agamben, Homo sacer, continuando con la discusión sobre la operosidad. En El uso de los cuerpos, nombra a Averroes dos veces en lugares fundamentales para pensar su llamada ontología medial. Como, «según Averroes -dice Agamben- la multitudo, en tanto sujeto genérico de la potencia de pensar, va siempre pensada en relación a la existencia de un solo filósofo que, a través de los fantasmas de su imaginación, se une al intelecto único, así la potencia del pensamiento de la que hablamos va siempre puesta en relación con el uso singular de una potencia común» que también llama «la potencia unitaria que constituye en forma-de-vida las múltiples formas de vida» (Agamben, 2014, p. 271). Aquí Agamben se acerca mucho más a las tesis sobre el intelecto que Averroes describe en sus comentarios al De ani$m a$ de Aristóteles. El intelecto ya no sólo aparece como una forma en la que vivimos como potencia, sino que su propio carácter separado de la especie lo muestra como el medio puro, usando la jerga benjaminiana, en el que el humano como tal resulta ser una singularidad imaginativa y no un sujeto dueño de su pensamiento.

Casi al final de esta obra, Agamben vuelve a poner a Averroes como una figura radical para pensar una ontología contraria al poder soberano que divide la vida humana y crea al hombre como tal.

En el pensamiento occidental -dice- el problema de la forma de vida ha emergido como problema ético (el ethos, el modo de vida de un individuo o de un grupo) o como problema estético (el estilo que el autor imprime sobre su obra). Sólo si se le restituye a la dimensión ontológica, el problema del estilo y del modo de vida podrá alcanzar su justa formulación»

y más adelante prosigue

«En la historia de la filosofía, el lugar en el que este problema ha tenido lugar es el averroísmo, como problema de la conjunción (copulatio) entre el individuo singular y el intelecto único» (Ibíd, p. 297).

En esta conjunción lo que se une, ya vimos que por medio de la imaginación, es la experiencia de un ser singular y el ser, unión que hace nacer un estilo, una modulación en el ser que es lo que propiamente se puede llamar, así, con guiones entre medio, una «forma-de-vida».

En 2005 Agamben prologa la obra de Coccia sobre el averroísmo y se refiere de manera expresa a algunas características que considera relevantes de Averroes para entender su propia filosofía. Concretamente, respecto a este gran problema de la potencia, Agamben dirá que «el intelecto es un ser de pura potencia, pero la potencia no es un accidente o el atributo de algo, sino un modo eminente del ser» (en Coccia, 2008, p. 14). Y luego dice algo que me 
parece fundamental para entender el problema ontológico del programa agambeniano. "Y existir como potencia - dice- no significa simplemente carecer de una forma actual, estar privado de formas; más bien significa ser capaz de recibir formas, no ser sino pura receptividad o, en el sentido etimológico del término, pasión» (Ibid). El pensamiento de Averroes sería para Agamben una vía ontológica totalmente separada de aquella que construyó el tomismo, que transforma la potencia del ser averroísta en pura voluntad divina, separando el propio cuerpo, una vez más, en una dualidad material-espiritual, llevando hacia la teología esta división que ya se pronunciaba tenuemente en la filosofía aristotélica (Cf. Agamben, 2007, p. 99).

Averroes ocupa, entonces, un lugar central en la filosofía no nihilista de Agamben, en tanto filósofo que ha sido capaz de comprender la fractura producida por el peripatetismo, recomponiéndolo a través de la radicalización de una tesis aristotélica, estableciendo la separación entre el intelecto material y los seres singulares, no para avanzar hacia una trascendencia, sino al contrario, para colocar lo común como el lugar en el que es posible una existencia singular que no puede ser construida biopolíticamente sino llevando a cabo una operación de corte, tarea que inicia la teología cristiana y consuma la modernidad.

El caso de Roberto Esposito es un poco más tardío y aunque buena parte de su filosofía podría perfectamente colgarse del hilo secreto del averroísmo, no es sino hasta la publicación de su libro Dos. La máquina de la teología política y el lugar del pensamiento que él mismo afirma ser parte de una tradición en la que incluye a Averroes. El problema de Esposito no es tan diferente al de Agamben, porque lo que está en juego en su manera de pensar la biopolítica es la búsqueda por romper con esa fractura al interior del cuerpo que es lo que permite el surgimiento de la figura teológica de la persona y abrir la política hacia el lugar de lo común.

Es difícil -dice en su libro Tercera persona- para una tradición como la nuestra, embebida desde sus orígenes en teología política, privar a la categoría de decisión de su conexión con las de individuo y soberanía -conjugarla, antes que con la persona, con lo impersonal (Esposito, 2009, p. 33).

También Esposito lleva a cabo un ejercicio arqueológico en busca de esos dispositivos sutiles que van convirtiendo al humano en un ser fracturado, incapaz de vivir en la potencia de lo común, mas, por cierto muy seguro de ser propietario de sí mismo.

En Esposito debemos tener claro que su ontología, en la que lo común juega un rol fundamental, es una que muestra al individuo singular como un 
ser expuesto que requiere a los otros. Es en esa debilidad constitutiva del humano donde adquiere sentido una política que rompa con las ataduras de la subjetividad moderna.

Cum -dice Jean Luc Nancy prologando a Esposito- es algo que nos expone, nos pone los unos frente a los otros, nos entrega los unos a los otros, nos arriesga los unos contra los otros y todos juntos nos entrega a lo que Esposito (el bien llamado expuesto) llama para concluir 'la experiencia', la cual no es otra sino la de ser con... (Esposito, 2007).

Es ahí donde resulta gravitante la figura de Averroes. Esposito reconstruye en el libro Dos la trama de la polémica contra el averroísmo latino. Se interesa por el carácter maldito de Averroes, pero sobre todo, ve en esa figura de la filosofía árabe una vía de escape. Contrario a todo antropocentrismo

Averroes - dice Esposito- se sitúa en una linea que de Siger de Brabante a Pomponazzi, tiende a acercar el destino del hombre al de los otros seres vivientes, aún sin perder la diferencia relativa a su peculiar actitud cognoscitiva. El operador primero de tal pasaje es el reasentamiento del intelecto fuera de los confines del individuo (Esposito, 2013, p. 162).

Lo que se articula en Averroes para Esposito es la posibilidad de pensar la existencia del humano fuera de los márgenes del sujeto, lo que tendría un impacto no sólo noético, sino también -y quizá sobre todo- político, pues tal como Aquino acusaba a Averroes de haber hecho inoperante la ley de la ciudad, que al recaer en lo común impedía el castigo y la recompensa individual en términos positivos, Esposito dirá que

Es evidente que, rompiendo la relación entre pensamiento y sujeto, o reinterpretándola en una clave que hace del sujeto el tránsito, en vez del propietario, del pensamiento, Averroes disgrega no solo un bloque metafísico, sino un horizonte teológico-político articulado en torno a la semántica de la persona (Ibíd., p. 163).

Al igual que en Agamben, aparece aquí una búsqueda por descentrar la existencia humana, sacándola de la excepcionalidad de la máquina teológicopolítica que a fin de cuentas presenta la propia vida humana fragmentada internamente y expuesta hacia la enemistad como fundamento metafísico de toda política. Pero, dice Esposito

Si la voluntad no responde más a un intelecto implantado al interior del cuerpo individual, sino que entra en un contacto provisorio y nunca definitivo con una potencia común de carácter impersonal, también sus opciones serán internas a un interés colectivo que comprende a la especie humana en su complejidad. Se transforma, en tal caso, el significado completo de aquello que se define como política -no más el dominio de sí orientado a dominar a los otros, sino la elaboración de un bien que desde el inicio pertenece a todos. De este modo, aquella 
máquina teológica-política, que en el dispositivo de la persona une a los hombres separándolos, se transforma en una teoría del intelecto separado que los unifica en un destino común (Ibíd., p. 165).

Lo que resulta fundamental tanto para Agamben como para Esposito es pensar una fuerza inmanente que funcione como un tercero frente a la separación que opera sobre el cuerpo la teología occidental. La forma-de-vida funciona como una comprensión del cuerpo fundada en la imposibilidad de la intervención teológico-política. El intelecto material en este sentido se muestra como un dispositivo antídoto de la teología política en tanto hace de cada individuo una singularidad perteneciente a un todo común. Se podría decir, asimismo, que el intelecto material es el elemento que permite a Agamben, a su vez, pensar en términos efectivos una potencia destituyente, con la que termina el proyecto Homo sacer. Lo que tenemos frente a nosotros es nada menos que una búsqueda en el averroísmo de una ontología capaz de desarticular la máquina teológico-política, que en Agamben funciona a la base de la excepción y en Esposito articula el concepto moderno de persona.

\section{LA IMAGEN DESEADA}

Tanto Coccia como Brenet, por su parte, han intentado mostrar cómo Averroes y el averroísmo son claves para la comprensión de una ética singular, signada por una relación de amor entre el ser singular y el intelecto común.

Pensar para Averroes -indica Brenet-, significa para el individuo humano 'unirse' [se joindre] al inteligible por el medio de sus imágenes (de las cuales el inteligible es extraído) y, al hacer esto, 'unirse' [se joindre] formalmente al intelecto agente, productor del inteligible en cada acto (Brenet, 2018, p. 105).

Este «unirse» aparece en el Gran Comentario al De Anima de Aristóteles amorosamente como una copulatio entre el intelecto y las formas de la imaginación (Averroes, 2004, 148). Esto da a la imagen un estatus especial al interior de la noesis averroísta, en tanto «operador de individualización del intelecto y el lugar donde la transparencia absoluta del pensamiento deviene cognoscibilidad de algo» (Coccia, 2008, p. 274), de modo que entre la continuidad de las imágenes y el pensamiento en que habita el humano funcionan dos tiempos de la experiencia, el instante de la imagen y el eterno del pensamiento.

La facultad que permite a Averroes hacer de puente entre intelecto e imagen es la imaginación, de modo que, efectivamente, en el proceso intelectivo aparece una suerte de doble sujeto pensante. «Todos los pensamientos en acto deben pensarse como lo que se genera en la tensión y en la polaridad que se constituyen entre dos sujetos extremos, uno de los cuales - dice Coccia- es el 
intelecto material y el otro es la imaginación humana, la única fuerza capaz de depositar en el intelecto el esbozo de una forma» (Ibíd., p. 278). Lo que define la experiencia humana, entonces, no es tanto el hecho de pensar, sino el de hacer copular la intelección con la imaginación de cuyo encuentro surge una proyección imaginativa de las imágenes del mundo y una introyección de los inteligibles en nosotros. El pensamiento, como tal ocurre siempre como una exposición al afuera e interiorización del afuera, haciendo difícil, si no imposible, la idea de un yo soberano, capaz de darse gobierno a sí mismo (Cf. Ibíd., p. 372).

Existen al menos dos puntos de vista respecto a las consecuencias que puede traer la separación del intelecto. Por una parte, podríamos entender que dadas sus características de eterno y común, el intelecto podría anular toda singularidad individual, pero también toda historia, dado que esta entidad externa supera todo horizonte temporal. En él todo ha sido escrito, todo se ha dicho, todo se ha imaginado. Es un intelecto que condena al humano a repetir lo que ha existido desde siempre. Como dice Brenet, en este caso el intelecto se parecería más a una pagina ennegrecida absolutamente con tinta que a una tabula rasa como había imaginado el propio Aristóteles el intelecto (Brenet, 2018 , p. 110). Tal posición frente al intelecto averroísta anularía incluso al propio intelecto, en tanto éste ha sido siempre ya en acto, incapaz de acceder a una forma potencial. Nunca habría un inicio del pensamiento ni un final. Tal es la crítica que hace Aquino al averroísmo, que para la salvación de las almas necesita la existencia de un individuo que piensa y más aún, de un inicio del propio pensamiento (Cf. Aquino, 2008, pp. 155-156). El pensamiento de Averroes, si lo consideramos sólo desde la idea simplificada de un intelecto separado y eterno, no conduciría a otra cosa que a la negación de toda experiencia humana, o peor aún, del propio intelecto si es que éste se nutre de las formas de la imaginación que ya estarían dichas, escritas y reflejadas en el intelecto desde siempre.

Y es aquí donde aparece un asunto fundamental para comprender el intelecto averroísta hoy. Si es cierto que el intelecto trasciende absolutamente la experiencia individual de los hombres, al mismo tiempo los seres singulares que somos llenamos el intelecto por medio la imaginación y ésta a su vez no funciona sin deseo. «Aquello de lo que el alma dispone, en efecto -dice Brenet-, aquello que moviliza para pensar a voluntad sin depender más, como en el caso de la sensación, de los encuentros mundanos, es, en primer lugar, el fantasma» (Brenet, 2018, p. 113). El fantasma no es simplemente el objeto, sino la imagen que proyecta en nosotros, que imaginamos y transformamos constantemente. «Lo que justifica la necesidad del fantasma no es únicamen- 
te -continúa Brenet- la presentación del objeto del pensamiento, sino la de un objeto del deseo, o mejor, la de la dimensión deseable de todo objeto del pensamiento» (Ibid.).

En este mismo sentido Agamben dirá que

La historia de la humanidad es siempre historia de fantasmas y de imágenes, porque es en la imaginación donde tiene lugar la fractura entre lo individual y lo impersonal, lo múltiple y lo único, lo sensible y lo inteligible y, a la vez, la tarea de su dialéctica recomposición

y aún más

las imágenes son el resto, la huella de todo lo que los hombres que nos han precedido han esperado y deseado, temido y rechazado. Y puesto que es en la imaginación donde algo como la historia se ha hecho posible, es también en la imaginación donde ésta debe decidirse de nuevo una y otra vez» (Agamben, 2010, p. 53).

Fundamental resulta, entonces, atender al hecho de que con el intelecto se da una relación que hace existir tanto al humano como al propio intelecto y en esta relación participan de manera inseparable el fantasma, la imaginación $\mathrm{y}$ el deseo.

El pensamiento y el conocimiento - dice Coccia- no necesitan de un sustrato que los haga reales y actuales, sino de algo que les permita determinarse, darse una forma. Y es en la imagen donde éstos encuentran ese aspecto (Coccia, 2008, p. 296).

En este sentido, en este vínculo amoroso [copulatio] del ser singular con lo eterno es que se produce la historia y la biografía, pero a diferencia de la manera en que han comprendido la razón los modernos, la individualidad averroísta define menos una subjetividad que una actualización por medio del vínculo entre lo más situado y lo eterno. «La singularidad no define el ser de una idea sino su uso, su actualización» (Ibid., p. 301).

\section{REFERENCIAS BIBLIOGRÁFICAS}

ÁBED YABRI, M. (2001). El legado filosófico árabe, Alfarabi, Avicena, Avempace, Averroes, Abenjaldún, lecturas contemporáneas. Madrid, Editorial Trotta. AGAMBEN, G. (2005). La potenza del pensiero. Saggi e conferenze. Vicenza, Neri Pozza.

(2006). Estancias. La palabra y el fantasma en la cultura occidental. Valencia, Pre-Textos. 
(2007). Il Regno e la Gloria. Per una genealogia teologica dell'economia e del governo. Homo sacer, II, 2. Vicenza, Neri Pozza.

(2010). Ninfas. Valencia, Pre-Textos.

(2014). L'uso dei corpi. Homo sacer, IV, 2. Vicenza, Neri Pozza.

AQUINO, T. (2005). Sobre la unidad del intelecto contra los averroístas. Navarra, EUNSA.

AVERROES [Abū-1-Walīd Ibn Rušd]. (2004). Sobre el intelecto. Madrid, Editorial Trotta.

(2011). Exposición de la «República» de Platón. Madrid, Tecnos.

BRENET, J-B. (2013) Averroès a-t-il inventé une théorie des deux sujets de la pensée? Tópicos. [Online] 29 (1), 53. Disponible en, doi,10.21555/top.v29i1.212. (2018) Averroes el inquietante. Santiago, Metales Pesados.

BYRON, M. (2013). The Aristotelian Crescent, Medieval Arabic Philosophy in the Poetics of Ezra Pound. Marshall, S.; Cusack, C. (Eds.) The Medieval Presence in the Modernist Aesthetic, Unattended Moments. Leiden, Brill.

COCCIA, E. (2008). Filosofía de la imaginación. Averroes y el averroísmo. Buenos Aires, Adriana Hidalgo editora.

DE LIBERA, A. (2000). Pensar en la Edad Media. Barcelona, Anthropos. (2013). L'invention du sujet moderne. Cours du Collège de France 20132014. Paris, Vrin.

ESPOSITO, R. (2007). Communitas. Origen y destino de la comunidad. Amorrrortu, Buenos Aires.

(2009). Tercera persona. Política de la vida y filosofía de lo impersonal. Amorrortu, Buenos Aires.

(2013). Due. La macchina della teologia politica e il posto del pensiero. Torino, Einaudi.

GAGLIARDI, A. (1998). Scriture e Storia, Averroismo e Cristianesimo. Lorenzo de' Medici - Sperone Speroni - Torquato Tasso - Giordano Bruno. Catanzaro, Rubbettino Editore.

(2002). Tommaso D’aquino e Averroè. La visione di Dio, Catanzaro, Rubbettino Editore.

LICATA, G. (2017). Leggere Spinoza alla luce della tradizione averroista ebraica. Un resoconto delle recenti acquisizioni storiografiche. O que nos faz pensar, v. 26, n. 41, pp.45-55.

BARRERA, J. (2018). Aristóteles en el Occidente latino, Santo Tomás, Averroes y los averroístas. Hypnos 40 (1), 66-76.

RENAN, E. (1866). Averroès et l'averroïsme, essai historique. Paris, Michel Lévy frères. 
Mauricio Guillermo Amar Díaz es profesor del Centro de Estudios Árabes de la Universidad de Chile.

Lineas de Investigación:

Filosofía Árabe medieval y contemporánea, Islam, Filosofía política contemporánea Publicaciones recientes:

(2018). Ética de la imaginación. Averroísmo, uso y orden de las cosas. Santiago de Chile: Editorial malamadre.

(2017). «Contrapunto y mundanidad como herramientas De la crítica en Edward W. Said». Discusiones Filosóficas, 18(30), 107-124.

Correo electrónico:mgamar@uchile.cl 
